\title{
Pengaruh Kepuasan Kerja Dan Stress Kerja Terhadap Produktivitas Kerja Karyawan Pada PT. Sinar Surya Baja Profilindo
}

\author{
Kenny ${ }^{1)}$ \\ Heri Satrianto ${ }^{2)}$ \\ Manajemen, Universitas Buddhi Dharma, Banten, Indonesia
}

\begin{abstract}
Abstrak
Tujuan penelitian ini adalah: Untuk menganalisis pengaruh kepuasan kerja terhadap produktivitas kerja pada PT. Sinar Surya Baja Profilindo. Untuk menganalisis pengaruh stres kerja terhadap produktivitas kerja karyawan pada PT. Sinar Surya Baja Profilindo. Untuk menganalisis pengaruh kepuasan kerja dan stres kerja secara simultan terhadap produktivitas kerja karyawan pada PT. Sinar Surya Baja Profilindo.

Metode analisis dalam penelitian ini menggunakan regresi linier berganda. Sampel penelitian adalah 80 karyawan menggunakan simple random sampling. Teknik pengumpulan data dilakukan dengan menyebarkan kuesioner dan dibudidayakan dengan menggunakan SPSS 25.0. Hasil uji t pada variabel kepuasan kerja adalah 2.205, dengan nilai signifikansi 0,000. Artinya kepuasan kerja memiliki pengaruh signifikan terhadap produktivitas kerja. Hasil uji $\mathrm{t}$ pada variabel stres kerja adalah 3,018 dengan nilai signifikansi 0,000. Ini berarti stres kerja memiliki pengaruh signifikan terhadap produktivitas kerja. Hasil uji $\mathrm{F}$ adalah 154,526, itu berarti kepuasan kerja dan stres kerja memiliki pengaruh signifikan terhadap produktivitas kerja. Nilai koefisien determinasi (R2) untuk X1 dan X2 adalah 0,700, itu berarti turnover intention dapat dipengaruhi oleh kepuasan kerja dan stres kerja sekitar 70,0\%, kemudian faktor lain sekitar 30,0\%. Rumus regresi linier untuk hipotesis 1 adalah $Y=0,507+0,203 X 1$. Rumus regresi linier untuk hipotesis 2 adalah $\mathrm{Y}=0,507+0,518 \mathrm{X} 2$. Rumus regresi berganda untuk hipotesis 3 adalah $\mathrm{Y}=0,507+$ $0,203 \times 1+0,518 \times 2$
\end{abstract}

Kata Kunci : Kepuasan Kerja, Stress Kerja, Dan Produktivitas Kerja 


\section{Abstract}

The purpose of this study are: To analyze the effect of job satisfaction on work productivity at PT. Sinar Surya Baja Profilindo. To analyze the effect of job stress on work productivity of employees at PT. Sinar Surya Baja Profilindo. To analyze the effect of job satisfaction and job stress simultaneously on work productivity of employees at PT. Sinar Surya Baja Profilindo.

The method of analysis in this study using multiple linear regression. The sample is 80 employees using simple random sampling. Data collection techniques were carried out by distributing questionnaires and cultivated using SPSS 25.0. Result of t test on job satisfaction variable is 3,018, with significance value 0,000. This means that job satisfaction has a significant effect on work productivity. The result of $t$ test on work stress variable is 7,569 with significance value 0.000. This means that job stress has a significant effect on work productivity. F test result is 154,526, it means job satisfaction and job stress have a significant influence on work productivity. The value of determination coefficient (R2) for X1 and $X 2$ is 0,700 , that means turnover intention can be influenced by job satisfaction and job stress about 70,0\%, then other factor about 30.0\%. The linear regression formula for hypothesis 1 is $Y=0.507+0.203 X 1$. The linear regression formula for hypothesis 2 is $Y=$ $0.507+0.518 X 2$. The multiple regression formula for hypothesis 3 is $Y=0.507+0.203 X 1$ $+0,518 \times 2$

\section{Keyword: Job Satisfaction, Work Stress, And Work Productivity}

\section{PENDAHULUAN}

Faktor penentu keberhasilan suatu perusahaan bukan dari teknologi yang di pakai di perusahaan tersebut melainkan dari sumber daya yang dimilikinya. Sumber daya manusia selalu berhubungan pada setiap suatu sumber daya sebagai penentu keberadaan dan peran dalam memeberikan kontribusi dalam pencapaian tujuan organisasi secara efektif dan efisien. Sumber daya professional telah menjadi suatu kebutuhan strategis suatu perusahaan atau organisasi.

Umumnya perusahaan selalu ingin meningkatkan produktivitas kerja agar perusahaan tersebut selalu berkembang. Dalam hubungan dengan peningkatan produktivitas perusahaan, salah satu langkah yang dapat dilakukan meningkatkan atau memperbaiki situasi lingkungan kerja. Maksud hal ini agar adanya ketersediaan fasilitas-fasilitas di dalam lingkungan perusahaan, sehingga karyawan dapat terpacu untuk meningkatkan produktivitas kerjanya.

Kepuasan Kerja adalah keadaan emosional yang menyenangkan atau tidak menyenangkan dimana karyawan memandang pekerjaan mereka. Kepuasan kerja mencerminkan perasaaan seseorang terhadap pekerjaan mereka, yang biasanya tampak dalam sikap positif para karyawan terhadap pekerjaan dan segala sesuatu yang dihadapi di lingkungan kerjanya.

Untuk itu merupakan keharusan bagi perusahaan untuk mengenali faktor-faktor apa saja yang membuat karyawan puas bekerja di perusahaan. Dengan tercapainya kepuasan kerja karyawan, produktivitasnya pun akan meningkat. Banyak faktor yang mempengaruhi kepuasan kerja karyawan, diantaranya adalah kesesuaian pekerjaan, kebijaksanaan organisasi termasuk kesempatan untuk berkembang, lingkungan kerja dan perilaku atasan. Jika karyawan merasa tidak puas maka ada beberapa hal yang mungkin akan dilakukan yaitu, karyawan akan berfikir untuk meninggalkan pekerjaan mereka. Kepuasan kerja cenderung berpusat pada produktivitas karyawan yang akan memberikan efek atau dampak pada 
karyawan itu sendir. Jika karyawan tidak puas dengan pekerjaan mereka maka karyawan tersebut akan menjadi stress dan akan menghambat pekerjaan serta menurunkan produktivitas mereka. Kepuasan kerja karyawan dipengaruhi oleh kondisi kerjanya, sehingga produktivitas seseorang akan meningkat bila dalam organisasi ada aktivitas hubungan manusiawi yang membawa kepuasan sosial dan psikologi pekerja. Kepuasan sosial menuntut kebebasan bersosialisasi dalam pelaksanaan tugas, sedangkan psikologis dapat terpenuhi dengan memberi kesempatan kepada seseorang untuk berpartisipasi dalam pengambilan keputusan manajerial.

Dalam ilmu manajemen ada istilah “ Happy Employee, Happy Customer” yang berarti sebelum memuaskan pelanggan, harus terlebih dahulu memuaskan pekerja. Kepuasan kerja pada dasarnya merupakan hal yang bersifat individual, setiap individual memiliki tingkat kepuasan kerja yang berbeda-beda. Berdasarkan survei awal pada PT.Sinar Surya Baja Profilindo ternyata tidak semua pegawai merasa puas dengan pekerjaan dan gaji mereka sehingga pegawai mempunyai tekanan pekerjaan yang begitu besar. Fakta yang dirasakan para pegawai tersebut berpengaruh terhadap produktivitas mereka dan pada akhirnya ada pegawai yang memutuskan resign dari pekerjaannya karena ketidakpuasannya tersebut.

Stress kerja adalah gangguan mental yang dihadapi seseorang akibat adanya tekanan. Tekanan ini muncul dari kegagalan individu dalam memenuhi kebutuhan atau keinginannya. Tekanan ini bisa berasal dari dalam diri seseorang atau dari luar. Termasuk tuntutan yang dikaitkan dengan apa yang sangat diinginkannya dan dihasilkannya, sehingga dapat di persepsikan sebagai tindak pasti atau penting.

Menurut ( Nadeem Et Al, 2011) menunjukan bahwa :

"stress kerja berpengaruh secara negatif terhadap produktivitas kerja karyawan. Stress kerja yang dialami oleh karyawan PT.Sinar Surya Bajaprofilindo merupakan faktor beberapa konstruk, dan faktor-faktor ini secara signifikan terkait satu sama lain. Stress dalam bekerja terkait dengan jumlah pekerjaan dan variabel organisasi. Stress memiliki efek psikologis dan sosial, efek ini dapat mengakibatkan produktivitas karyawan menjadi menurun”.

Produktivitas kerja adalah kemampuan karyawan dalam berproduksi dibandingkan dengan input yang digunakan. Permasalahannya sekarang, yaitu bagaimana menciptakan produktivitas yang diinginkan oleh suatu perusahaan, karena ukuran produktivitas tiap perusahaan akan berbeda tergantung dari konsep yang diterapkan. Produktivitas akan berbeda di masing-masing perusahaan sesuai dengan kondisi, potensi, dan kekurangan serta harapanharapan yang dimiliki oleh perusahaan yang bersangkutan dalam jangka pendek dan jangka panjang..

Penghambat produktivitas karyawan di perusahaan adalah stress kerja yang terlalu berlebihan pada karyawan dan dapat menimbulkan efek yang buruk bagi karyawan. Karyawan yang bekerja dalam volume banyak belum tentu mendapatkan tekanan yang begitu besar ketimbang karyawan yang bekerja dengan volume sedikit. Menurut (Al, 2011, p. 90) sumber stress kerja adalah karena kondisi pekerjaan, masalah peran, hubungan interpersonal,kesempatan pengembangan karir, dan struktur organisasi. Kondisi kerja yang buruk dapat berpotensi penyebab karyawan mudah jatuh sakit, mudah stress, sulit berkosentrasi, dan menurunya produktivitas kerja.

\section{LANDASAN TEORI}

\section{Pengertian Kepuasan Kerja}

Menurut (Sinambela, 2016, hal. 303) mengatakan bahwa : 
"Kepuasan Kerja adalah perasaan seseorang terhadap pekerjaannya yang dihasilkan oleh usahanya sendiri dan didukung oleh hal-hal yang dari luar dirinya, atas keadaan kerja, hasil kerja, dan kerja itu sendiri"

Menurut (Handoko, 2014, p. 193) mengatakan bahwa :

"Kepuasan Kerja adalah keadaan emosional yang menyenangkan dimana para karyawan memandang pekerjaan mereka"

Menurut (Hasibuan, 2017, p. 203) mengatakan bahwa :

"Kepuasan Kerja adalah kunci pendorong moral, kedisiplinan, dan prestasi kerja karyawan dalam mendukung terwujudnya perusahaan"

\section{Pengertian Stress Kerja}

Menurut (Handoko, 2014, p. 200) mengatakan bahwa :

"Stress Kerja adalah suatu kondisi ketegangan yang mempengaruhi emosi,proses berpikir, dan kondisi seseorang"

Menurut (Hasibuan, 2017, p. 204) mengatakan bahwa :

"Stress kerja adalah suatu kondisi ketegangan yang mempengaruhi emosi, proses berpikir, dan kondisi seseorang"

Menurut (Sinambela, 2016, hal. 472) mengatakan bahwa :

"Stress Kerja adalah perasaan tertekan yang dialami pegawai dalam menghadapi pekerjaan"

\section{Pengertian Produktivitas Kerja}

Menurut (Sutrisno, 2014) Produktivitas kerja adalah rasio dari hasil kerja dengan waktu yang dibutuhkan untuk menghasilkan suatu produk dari seorang tenaga kerja.

Menurut (Sedarmayanti, 2016) Produktivitas Kerja adalah Perbandingan antara hasil yang dicapai dan keseluruhan daya/ factor produksi yang dipergunakan.

Menurut (Sauermann, 2016) Produktivitas kerja dapat di definisikan sebagai rasio antara ukuran output dan input produktivitas pekerja yang dapat diukur untuk memperhitungkan perbedaan terhadap relatif masukan dan ukuran agregat di dalam suatu perusahaan

\section{METODE PENELITIAN}

\section{Jenis dan Sumber Data}

Pengumpulan data dimaksudkan untuk mengadakan perbandingan antara suatu teori dengan pelaksanaan pada perusahaan yang sebenarnya dalam kaitannya dengan teori tersebut. Dengan melakukan penelitian berarti akan diperoleh suatu prosedur ilmiah yang sistematis, sehingga masalah yang diangkat dapat terjawab dengan lebih lengkap dan jelas.

Dalam pengumpulan data yang diperlukan, penulis menggunakan teknik-teknik sebagai berikut:

a. Riset Kepustakaan ( Library Research)

Merupakan teknik pengumpulan data dengan cara membaca dan mempelajari buku-buku dan literatur yang berhubungan dengan masalah yang akan dibahas.

Dengan riset kepustakaan ini akan diperoleh data sekunder yang diperlukan yang berkaitan dengan pembahasan dari pada skripsi ini.

b. Riset Lapangan (Field Research)

Merupakan metode pengumpulan data dengan cara mengadakan penelitian langsung pada pihak yang bersangkutan, sehingga diperoleh data primer yang dapat dipastikan kebenarannya. Adupun pengumpulan data ini dengan cara:

c. Kuesioner 
Teknik yang dilakukan dengan memberikan beberapa pernyataan kepada objek penelitian agar diisi dan dijawab dengan tujuan untuk menggali informasi, tanggapan, serta pendapat dari responden.

Dalam penelitian ini jenis data yang digunakan adalah data primer dan data sekunder.

1. Data primer adalah data yang diperoleh secara langsung melalui kegiatan penelitian (riset) pada sumber-sumber yang berhubungan langsung.

2. Data sekunder adalah data yang diperoleh berdasarkan pengumpulan bahanbahanstudi dengan cara membaca, mencatat, dan mempelajari buku-buku serta sumber-sumber data lainya yang bersifat teoritis dan berkaitan.

\section{Populasi dan Sampel}

1) Sampel

Menurut Sudaryono (2011:207) dalam bukunya Metode Penelitian PenelitianPendidikan menyatakan bahwa:

"Sampel adalah bagian dari jumlah dan karakteristik yang dimiliki oleh populasi tersebut."

Untuk menentukan ukuran sampel dari suatu populasi, terdapat bermacam-macam cara. Salah satunyadengan cara Slovin :

$$
\mathrm{n}=\frac{\mathrm{N}}{1+\mathrm{Ne}^{2}}
$$

Keterangan :

$\mathrm{n}=$ ukuran sampel

$\mathrm{N}=$ ukuran populasi

e $=$ tingkat kesalahan $(5 \%)$

Berdasarkan rumus pengukuran sampel tersebut, jumlah populasi 100 karyawan maka dapat dihitung jumlah sampel yang diambil adalah sebanyak 100 karyawan terpilih.

$$
\begin{aligned}
\mathrm{n} & =\frac{N}{1+N(e)^{2}} \\
& =\frac{100}{1+100(0.05)^{2}} \\
& =80 \text { orang }
\end{aligned}
$$

\section{Teknik Pengumpulan Data}

Dalam hal ini penulis menggunakan sampel acak sederhana, setiap elemen populasi mempunyai peluang yang sama untuk terpilih menjadi sampel. Proses pengambilan sampel acak sederhana sederhana relatif mudah. Namun semakin besar populasi, proses pengambilan sampel akan semakin rumit

\section{HASIL DAN PEMBAHASAN}

\section{Hasil Analisis Data}

Uji Validitas dan Reliabilitas Variabel Kepuasan Kerja (X1) 
Dalam penelitian ini, peneliti membuat 11 pernyataan tentang kepuasan kerja untuk mengetahui apakah semua pernyataan reliabel maka dilakukan uji reliabilitas dengan hasil sebagai berikut:

Tabel 1

Reliability Statistics

\begin{tabular}{|r|r|}
\hline $\begin{array}{c}\text { Cronbach's } \\
\text { Alpha }\end{array}$ & \multicolumn{1}{|c|}{$\begin{array}{c}\text { Items } \\
\text { Items }\end{array}$} \\
\hline .798 & 11 \\
\hline
\end{tabular}

Sumber : SPSS 25.0

Dari tabel diatas dapat dijelaskan sebagai berikut:

1. Pada tabel Reliability Statistics di atas terlihat bahwa nilai Cronbach's Alpha adalah sebesar 0,798 dengan jumlah pernyataan 11 pernyataan.

2. Jika dibandingkan dengan nilai Alpha menurut Romie Priyastama (2017:170) dalam bukunya "Buku Sakti Kuasai SPSS Pengolahan Data dan Analisis Data", maka nilai Cronbach's Alpha yang cukup dapat diterima (acceptable) adalah yang bernilai 0,60.

3. Nilai Cronbach's Alpha dari variabel kepuasan kerja lebih besar daripada nilai $\alpha=$ 0,60 .

4. Jadi semua kuesioner tentang kepuasan kerja tersebut terbukti reliabel.

Tabel 2

Item Total Statistics

\begin{tabular}{|l|r|r|r|r|}
\hline & $\begin{array}{c}\text { Scale Mean if } \\
\text { Item Deleted }\end{array}$ & $\begin{array}{c}\text { Scale } \\
\text { Variance if } \\
\text { Item Deleted }\end{array}$ & $\begin{array}{c}\text { Corrected } \\
\text { Item-Total } \\
\text { Correlation }\end{array}$ & $\begin{array}{c}\text { Cronbach's } \\
\text { Alpha if Item } \\
\text { Deleted }\end{array}$ \\
\hline Minat Kerja & 35.9000 & 28.015 & .409 & .788 \\
\hline Sikap Kerja & 35.8625 & 27.082 & .653 & .773 \\
\hline Bakat & 35.9125 & 27.549 & .591 & .778 \\
\hline Keterampilan & 36.4000 & 23.509 & .772 & .746 \\
\hline Gaji & 36.8625 & 24.424 & .417 & .793 \\
\hline Dana Pensiun & 36.8500 & 26.458 & .731 & .766 \\
\hline Tunjangan & 37.4375 & 24.907 & .505 & .777 \\
\hline Promosi Kerja & 36.5750 & 27.083 & .238 & .812 \\
\hline Waktu Kerja & 36.6875 & 26.344 & .320 & .762 \\
\hline Penerangan & 37.2000 & 22.947 & .618 & .799 \\
\hline Keadaan & 36.0625 & 29.730 & .251 & \\
Ruangan & & & & \\
\hline
\end{tabular}

Sumber : SPSS 25.

Dari tabel diatas dapat dijelaskan sebagai berikut:

- Tabel Item-Total Statistics menunjukan hasil perhitungan validitas untuk 11 pernyataan. 
- Menentukan besarnya nilai $r$ tabel dengan ketentuan tingkat kepercayaan (degree of freedom - df) jumlah responden dikurangi 2 atau $80-2=78$ dengan tingkat signifikasi 5\% maka $r$ tabel sebesar 0,212.

- Membandingkan $\mathrm{r}_{\text {tabel }}$ dengan setiap butir $\mathrm{r}_{\text {hitung }}$ pernyataan dengan cara membandingkan output correlated item total correlation dengan 0,212 ( $\left.\mathrm{r}_{\text {tabel }}\right)$.

- Jika dibandingkan dengan $\mathrm{r}_{\text {tabel }}$ pada kolom correlated item total correlation, nilai $\mathrm{r}_{\text {hitung }}$ semua pernyataan tentang kepuasan kerja lebih besar dari $\mathrm{r}_{\text {tabel }}$ artinya semua pernyataan valid.

\section{Uji Validitas dan Reliabilitas Variabel Stress Kerja (X2)}

Dalam penelitian ini, penulis membuat sepuluh pernyataan tentang Stress kerja untuk mengetahui apakah semua pernyataan reliabel maka dilakukan uji reliabilitas dengan hasil sebagai berikut:

\section{Tabel 3}

Reliability Statistics

\begin{tabular}{|c|c|}
\hline $\begin{array}{c}\text { Cronbach's } \\
\text { Alpha }\end{array}$ & $\begin{array}{c}\text { N of } \\
\text { Items }\end{array}$ \\
\hline .687 & 10 \\
\hline \multicolumn{2}{|c|}{6} \\
\hline
\end{tabular}

Dari tabel diatas dapat dijelaskan sebagai berikut:

1. Pada tabel Reliability Statistics di atas terlihat bahwa nilai Cronbach's Alpha adalah sebesar 0,687 dengan jumlah pernyataan 10 pernyataan.

2. Jika dibandingkan dengan nilai Alpha menurut Romie Priyastama (2017:170) dalam bukunya "Buku Sakti Kuasai SPSS Pengolahan Data dan Analisis Data", maka nilai Cronbach's Alpha yang cukup dapat diterima (acceptable) adalah yang bernilai 0,60 .

3. Nilai Cronbach's Alpha dari variabel lingkungan kerja lebih besar daripada nilai $\alpha$ $=0,60$.

4. Jadi semua kuesioner tentang stress kerja tersebut terbukti reliable.

Tabel 4

\begin{tabular}{|l|r|r|r|r|}
\hline \multicolumn{5}{|c|}{ Item-Total Statistics } \\
\hline & $\begin{array}{c}\text { Scale Mean if } \\
\text { Item Deleted }\end{array}$ & $\begin{array}{c}\text { Scale Variance } \\
\text { if Item Deleted }\end{array}$ & $\begin{array}{c}\text { Corrected } \\
\text { Ittem-Total } \\
\text { Correlation }\end{array}$ & $\begin{array}{c}\text { Cronbach's } \\
\text { Alpha if Item } \\
\text { Deleted }\end{array}$ \\
\hline Beban Kerja & 33.5000 & 18.962 & .220 & .694 \\
\hline Tekanan & 33.0875 & 20.081 & .215 & .714 \\
\hline Konflik & 33.4625 & 17.872 & .458 & .648 \\
\hline Perubahan & 32.6250 & 18.440 & .535 & .649 \\
\hline Kebijakan & 33.6500 & 18.559 & .427 & .657 \\
\hline Aturan & 33.4125 & 17.790 & .249 & .686 \\
\hline Gaya Kepemimpinan & 33.3500 & 16.559 & .628 & .617 \\
\hline Kebisingan & 33.1375 & 17.816 & .286 & .676 \\
\hline Cuaca Panas & 33.1125 & 15.797 & .438 & .645 \\
\hline
\end{tabular}




\begin{tabular}{|l|r|r|r|r|}
\hline Lalu Lintas & 33.1000 & 16.015 & .473 & .637 \\
\hline
\end{tabular}

\section{Sumber : SPSS 25.0}

Dari tabel diatas dapat dijelaskan sebagai berikut:

- Tabel Item-Total Statistics menunjukan hasil perhitungan validitas untuk 10 pernyataan.

- Menentukan besarnya nilai $r$ tabel dengan ketentuan tingkat kepercayaan (degree of freedom - df) jumlah responden dikurangi 2 atau $80-2=78$ dengan tingkat signifikasi 5\% maka $r$ tabel sebesar 0,212.

- Membandingkan $r_{\text {tabel }}$ dengan setiap butir $r_{\text {hitung }}$ pernyataan dengan cara membandingkan output correlated item total correlation dengan 0,212 ( $\left.\mathrm{r}_{\text {tabel }}\right)$.

- Jika dibandingkan dengan $\mathrm{r}_{\text {tabel }}$ pada kolom correlated item total correlation, nilai rhitung semua pernyataan tentang stress kerja lebih besar dari $r_{\text {tabel }}$ artinya semua pernyataan valid.

Uji Validitas dan Reliabilitas Variabel Produktivitas Kerja Karyawan (Y)

Dalam penelitian ini, penulis membuat sepuluh pernyataan tentang produktivitas kerja karyawan untuk mengetahui apakah semua pernyataan reliabel maka dilakukan uji reliabilitas dengan hasil sebagai berikut:

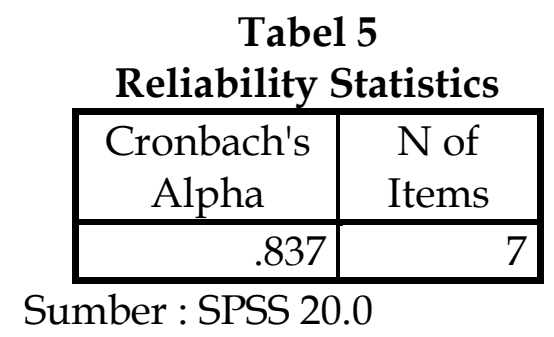

Dari tabel diatas dapat dijelaskan sebagai berikut:

1. Pada tabel Reliability Statistics di atas terlihat bahwa nilai Cronbach's Alpha adalah sebesar 0,837 dengan jumlah pernyataan 7 pernyataan.

2. Jika dibandingkan dengan nilai Alpha menurut Romie Priyatama (2017:170) dalam bukunya "Buku Sakti Kuasai SPSS Pengolahan Data dan Analisis Data", maka nilai Cronbach's Alpha yang cukup dapat diterima (acceptable) adalah yang bernilai 0,60 .

3. Nilai Cronbach's Alpha dari variabel motivasi kerja lebih besar daripada nilai $\alpha=$ 0,60 .

4. Jadi semua kuesioner tentang produktivitas kerja karyawan tersebut terbukti reliable.

Tabel 6

Item-Total Statistics

\begin{tabular}{|l|c|r|r|r|}
\hline & $\begin{array}{c}\text { Scale Mean if } \\
\text { Item Deleted }\end{array}$ & $\begin{array}{c}\text { Scale Variance } \\
\text { if Item Deleted }\end{array}$ & $\begin{array}{c}\text { Corrected } \\
\text { Item-Total } \\
\text { Correlation }\end{array}$ & $\begin{array}{c}\text { Cronbach's } \\
\text { Alpha if Item } \\
\text { Deleted }\end{array}$ \\
\hline Prestasi Kerja & 21.5125 & 13.139 & .588 & .821 \\
\hline
\end{tabular}


PRIMANOMICS : JURNAL EKONOMI DAN BISNIS - VOL. 17. No. 3 (2019)

Versi Online Tersedia di : https://jurnal.ubd.ac.id/index.php/ds

| 1412-632X (Cetak) | 2614-6789 (Online) |

\begin{tabular}{|l|r|r|r|r|}
\hline Output & 22.2750 & 10.911 & .822 & .778 \\
\hline Input & 21.6875 & 13.458 & .697 & .819 \\
\hline Pendidikan & 22.5500 & 9.795 & .582 & .838 \\
\hline Teknologi & 21.5125 & 13.139 & .588 & .821 \\
\hline Keluhan Karyawan & 23.0875 & 10.131 & .708 & .796 \\
\hline Quality Report & 22.3250 & 12.577 & .493 & .829 \\
\hline
\end{tabular}

Sumber : SPSS 25.0

Dari tabel diatas dapat dijelaskan sebagai berikut:

- Tabel Item-Total Statistics menunjukan hasil perhitungan validitas untuk 7 pernyataan.

- Menentukan besarnya nilai $r$ tabel dengan ketentuan tingkat kepercayaan (degree of freedom - df) jumlah responden dikurangi 2 atau 80- $2=78$ dengan tingkat signifikasi 5\% maka $r$ tabel sebesar 0,212.

- Membandingkan $r_{\text {tabel }}$ dengan setiap butir $r_{\text {hitung }}$ pernyataan dengan cara membandingkan output correlated item total correlation dengan 0,212 ( $\left.\mathrm{r}_{\text {tabel }}\right)$.

- Jika dibandingkan dengan $\mathrm{r}_{\text {tabel }}$ pada kolom correlated item total correlation, nilai rhitung semua pernyataan tentang Produktivitas kerja karyawan lebih besar dari $r_{\text {tabel }}$ artinya semua pertanyaan valid.

Tabel 7

Variables Entered/Removed ${ }^{a}$

\begin{tabular}{|l|l|l|l|}
\hline Model & \multicolumn{1}{|c|}{$\begin{array}{c}\text { Variables } \\
\text { Entered }\end{array}$} & $\begin{array}{c}\text { Variables } \\
\text { Removed }\end{array}$ & \multicolumn{1}{|c|}{ Method } \\
\hline 1 & & & $\begin{array}{l}\text { Stepwise } \\
\text { (Criteria: } \\
\text { Probability-of- } \\
\text { F-to-enter <= } \\
\text {.050, } \\
\text { Probability-of- } \\
\text { F-to-remove } \\
>=.100) . \\
\text { Stepwise } \\
\text { Kerja }\end{array}$ \\
& & & $\begin{array}{l}\text { Criteria: } \\
\text { Probability-of- } \\
\text { F-to-enter <= } \\
\text {.050, } \\
\text { Probability-of- } \\
\text { F-to-remove } \\
>=.100) .\end{array}$ \\
\hline
\end{tabular}

a. Dependent Variable: Produktivitas Kerja

Sumber : SPSS 25.0 
Pengaruh Kepuasan Kerja dan stress kerja merupakan variabel masukan (variabel intered) karena probabilitas dari pengaruh kepuasan kerja dan stress kerja memenuhi kriteria probabilitas, dimana probabilitas pengaruh kepuasan kerja dan stress kerja intensif dibawah 0,05.

Pengujian signifikasi kolerasi ini dilakukan dengan pengujian satu sisi, dimana dasar pengambilan keputusannya adalah berdasarkan probabilitas. Jika probabilitas $(\mathrm{P}>\mathrm{Alpha}=0,05)$ maka Ho diterima dan Ha ditolak, jika probabilitas < 0,05 maka Ho ditolak dan Ha diterima.

Tabel 8

\begin{tabular}{|c|c|c|c|c|c|c|c|}
\hline \multicolumn{8}{|c|}{ Model Summary } \\
\hline \multirow[b]{2}{*}{$\begin{array}{l}\text { Mod } \\
\text { el }\end{array}$} & \multirow[b]{2}{*}{$\mathrm{R}$} & \multirow[b]{2}{*}{$\begin{array}{c}\mathrm{R} \\
\text { Square }\end{array}$} & \multirow[b]{2}{*}{$\begin{array}{l}\text { Adjusted } \\
\text { R Square }\end{array}$} & \multirow[b]{2}{*}{$\begin{array}{l}\text { Std. Error of } \\
\text { the Estimate }\end{array}$} & \multicolumn{3}{|c|}{ Change Statistics } \\
\hline & & & & & $\begin{array}{l}\text { R Square } \\
\text { Change }\end{array}$ & F Change & df1 \\
\hline 1 & $.837^{a}$ & .665 & .660 & 2.31258 & .665 & 154.526 & 1 \\
\hline 2 & $.815^{b}$ & .700 & .692 & 2.20102 & .035 & 9.107 & 1 \\
\hline
\end{tabular}

Dari tabel diatas dapat dilihat bahwa :

- Kolom $\mathrm{R}$ untuk model 1 menunjukan bahwa angka koefisien korelasi yaitu sebesar 0,837. Hal ini berarti pengaruh antara kepuasan kerja terhadap stress kerja karyawan pada PT. Sinar Suya Baja Profilindo mempunyai pengaruh yang kuat.

- Kolom $\mathrm{R}$ Square untuk model 1 menunjukan angka $\mathrm{R}$ Square adalah (pengkuadratan dari koefisien korelasi atau 0,837 × 0,837 =0,700). $\mathrm{R}$ Square disebut juga koefisien determinasi. Hal ini berarti besarnya pengaruh kepuasan kerja terhadap stress kerja karyawan pada PT. Sinar Surya Baja Profilindo adalah $(70.0 \%)$ sedangkan sisanya $(100 \%-70.0 \%=30.0 \%)$ dipengaruhi faktor lain.

- R Square berkisar pada 0 sampai 1. Semakin besar angka R Square menunjukan semakin kuat pengaruh antar variabel dan sebaliknya.

- Kolom Adjusted R Square untuk model 1 adalah sebesar 0,660.

- Kolom Standar Error Of The Estimate untuk model 1 adalah sebesar 2,31258.

- Perhatikan pada tabel 4.43 (Descriptive Statictics) diatas bahwa nilai standar deviasi produktivitas kerja karyawan pada PT. Sinar Surya Baja Profilindo adalah sebesar 3.96751 yang jauh lebih besar dari Standar Error Of The Estimate yang hanya sebesar 2,31258.

- Kolom $\mathrm{R}$ untuk model 2 menunjukan bahwa angka koefisien korelasi yaitu sebesar 0,815. Hal ini berarti pengaruh antara kepuasan kerja dan stress kerja terhadap Produktivitas kerja karyawan pada PT. Sinar Surya Baja Profilindo pengaruh yang sangat kuat.

- Kolom $\mathrm{R}$ Square untuk model 2 menunjukan angka $\mathrm{R}$ Square adalah (pengkuadratan dari koefisien korelasi atau 0,815 × 0,815=0,664). $\mathrm{R}$ Square disebut juga koefisien determinasi. Hal ini berarti besarnya pengaruh kepuasan kerja dan stress kerja terhadap produktivitas kerja karyawan pada PT. Sinar Surya Baja Profilindo adalah sebesar (66.4\%), sedangkan sisanya $(100 \%-66,4 \%=$ $33,6 \%)$ dipengaruhi faktor lain. $\mathrm{R}$ Square berkisar 0 sampai 1, semakin besar 
angka $\mathrm{R}$ Square menunjukan semakin kuat pengaruh antar variabel dan sebaliknya.

- Kolom Adjusted R Square untuk model 2 adalah sebesar 0,692.

- Kolom Standar Error Of Estimate untuk model 2 adalah sebesar 2.20102.

- Perhatikan pada tabel 4.43 (Descriptive Statictics) diatas bahwa nilai standar deviasi produktivitas kerja karyawan pada PT. Sinar Surya Baja Profilindo adalah sebesar 3.96751 yang jauh lebih besar dari Standar Error Of The Estimate yang hanya sebesar 2.20102.

Tabel 9

\begin{tabular}{|c|c|c|c|c|c|c|}
\hline \multicolumn{7}{|c|}{ ANOVA $^{a}$} \\
\hline \multicolumn{2}{|c|}{ Model } & $\begin{array}{l}\text { Sum of } \\
\text { Squares }\end{array}$ & $\mathrm{df}$ & $\begin{array}{l}\text { Mean } \\
\text { Square }\end{array}$ & $\mathrm{F}$ & Sig. \\
\hline \multirow[t]{3}{*}{1} & Regression & 826.405 & 1 & 826.405 & $\begin{array}{r}154.52 \\
6\end{array}$ & $.000^{\mathrm{b}}$ \\
\hline & Residual & 417.145 & 78 & 5.348 & & \\
\hline & Total & 1243.550 & 79 & & & \\
\hline \multirow[t]{3}{*}{2} & Regression & 870.524 & 2 & 435.262 & 89.847 & $.000^{c}$ \\
\hline & Residual & 373.026 & 77 & 4.844 & & \\
\hline & Total & 1243.550 & 79 & & & \\
\hline
\end{tabular}

a. Dependent Variable: Produktivitas Kerja

b. Predictors: (Constant), Kepuasan Kerja

c. Predictors: (Constant), Kepuasan Kerja, Stress Kerja

Dari tabel diatas dapat dilihat bahwa :

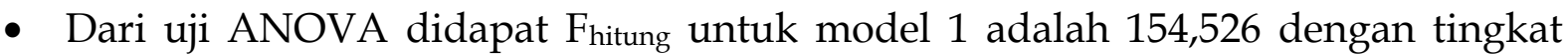
signifikan 0,000 dimana angka 0,000 $<0,05$ dan juga $F_{\text {hitung }}>F_{\text {tabel }}$ atau $154,256>$ 3,12, dengan demikian Ho ditolak dan Ha diterima artinya terdapat pengaruh linear antara variable kepuasan kerja dengan produktivitas kerja karyawan pada PT. Sinar Surya Baja Profilindo, maka model regresi tersebut sudah layak dan tepat untuk memprediksi produktivitas kerja karyawan pada PT. Sinar Surya Baja Profilindo.

- Dari uji ANOVA didapat $F_{\text {hitung }}$ untuk model 2 adalah 89,847 dengan tingkat signifikan 0,000 $<0,05$ dan juga $F_{\text {hitung }}>F_{\text {tabel }}$ atau 89,847 $>3,12$, dengan demikian Ho ditolak dan Ha diterima artinya terdapat pengaruh linear antara variabel stress kerja dengan produktivitas kerja karyawan pada PT. Sinar Surya Baja Profilindo, maka model regresi tersebut sudah layak dan tepat untuk memprediksi Produktivitas kerja karyawan PT. Sinar Surya Baja Profilindo. 
Tabel 10

Coefficients $^{\mathrm{a}}$

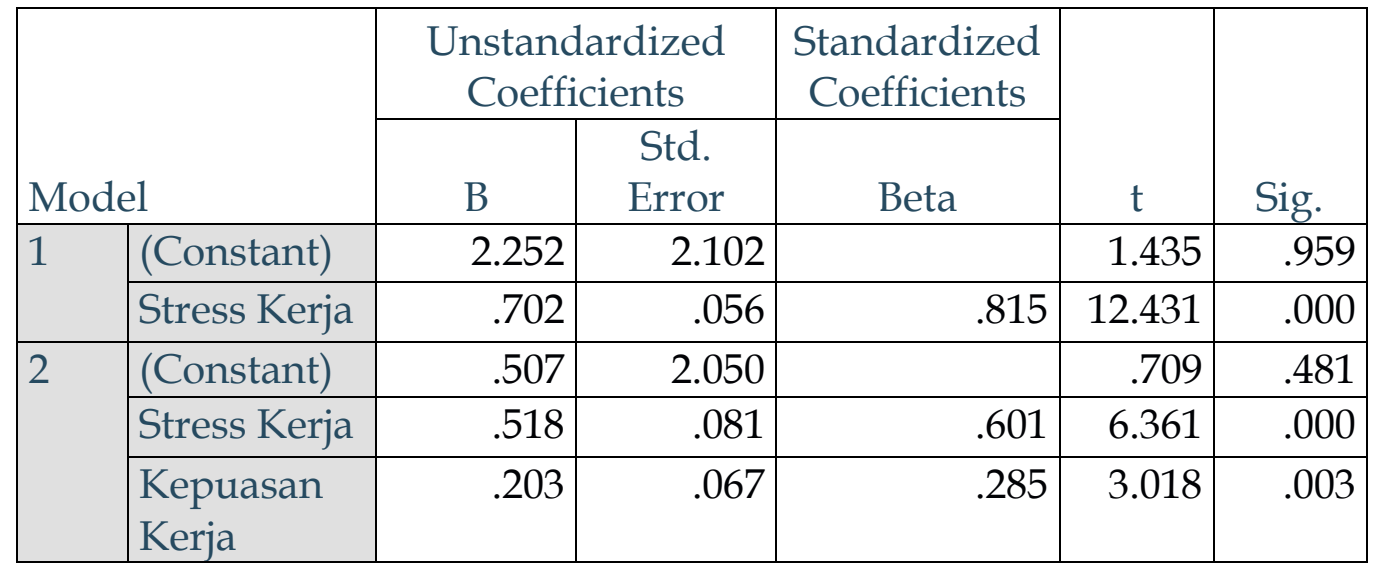

a. Dependent Variable: Produktivitas Kerja

Dari data diatas dapat dilihat bahwa :

- Untuk penyusunan persamaan regresi dari data diatas, dapat menggunakan nilai-nilai dari kolom B, yaitu kolom Unstandardized Coefficient. Dari kolom B ini dapat nilai konstan sebesar 0.507 sedangkan untuk nilai koefisien Kepuasan Kerja sebesar 0,203 dan nilai koefisien stress kerja sebesar 0,518.

- Dari nilai-nilai koefisien diatas didapat persamaan regresi sebagai berikut :

1. Analisa Persamaan Regresi X1 :

$$
\begin{array}{ll}
\mathrm{Y} & =\mathrm{a}+b_{1} X_{1} \\
\mathrm{a} & =\text { Konstan } \\
\mathrm{Y} & =\text { Produktivitas Kerja Karyawan } \\
X_{1} & =\text { Kepuasan Kerja } \\
X_{2} & =\text { Stress Kerja } \\
b_{1}, b_{2} & =\text { Koefisien Regresi } \\
\text { Maka diperoleh persamaan, } \\
\mathrm{Y} & =0.507+0,203 X_{1} \\
\mathrm{Y} & =\text { Produktivitas Kerja Karyawan } \\
X_{1} & =\text { Kepuasan Kerja } \\
X_{2} & =\text { Stress Kerja }
\end{array}
$$

2. Analisa Persamaan Regresi $X_{2}$ :

$$
\begin{array}{ll} 
& \mathrm{Y}=\mathrm{a}+b_{1} X_{1} \\
& \mathrm{a}=\text { Konstan } \\
\mathrm{Y} & =\text { Produktivitas Kerja Karyawan } \\
X_{1} & =\text { Kepuasan Kerja } \\
& X_{2}=\text { Stress Kerja } \\
& b_{1}, b_{2} \quad=\text { Koefisien Regresi } \\
& \text { Maka diperoleh persamaan, } \\
& \mathrm{Y}=0.507+0,518 X_{2}
\end{array}
$$


PRIMANOMICS : JURNAL EKONOMI DAN BISNIS - VOL. 17. No. 3 (2019)

Versi Online Tersedia di : https://jurnal.ubd.ac.id/index.php/ds

| 1412-632X (Cetak) | 2614-6789 (Online) |

$$
\begin{aligned}
& Y \quad=\text { Produktivitas Kerja Karyawan } \\
& X_{1}=\text { Kepuasan Kerja } \\
& X_{2} \quad=\text { Stress Kerja }
\end{aligned}
$$

3. Analisa Persamaan Regresi Secara Bersamaan :

$$
\begin{aligned}
\mathrm{Y}= & \mathrm{a}+b_{1} X_{1}+b_{2} X_{2} \\
\mathrm{a}= & \text { Konstan } \\
\mathrm{Y}= & \text { Produktivitas Kerja Karyawan } \\
X_{1}= & \text { Kepuasan Kerja } \\
& X_{2}=\text { Stress Kerja } \\
& b_{1}, b_{2} \quad=\text { Koefisien Regresi }
\end{aligned}
$$

Maka diperoleh persamaan,

$$
\begin{array}{ll}
\mathrm{Y} & =0.507+0,203 \mathrm{X} 1+0.518 \mathrm{X} 2 \\
\mathrm{Y} & =\text { Produktivitas Kerja Karyawan } \\
\mathrm{X} 1 & =\text { Kepuasan Kerja } \\
\mathrm{X} 2 & =\text { Stress Kerja }
\end{array}
$$

\section{Pembahasan}

- Pada saat variabel X1 (Kepuasan Kerja) terjadi peningkatan atau penurunan sebesar 1 poin maka variabel Y (Produktivitas Kerja Karyawan) akan mengalami peningkatan atau penurunan sebesar 0,203. Maka dari hasil analisis hipotesis pada tabel 4.45 diatas dapat disimpulkan bahwa ada pengaruh signifikan antara variable kepusasan kerja terhadap produktivitas kerja karyawan

- Pada saat variabel X2 (Stress Kerja) terjadi peningkatan atau penurunan sebesar 1 poin maka Y (Produktivitas Kerja Karyawan) akan mengalami peningkatan atau penurunan sebesar 0,518. Maka dari hasil analisis hipotesis pada tabel 4.45 diatas dapat disimpulkan bahwa ada pengaruh signifikan antara variabel stress kerja terhadap produktivitas kerja karyawan.

- Untuk regresi berganda, angka korelasi Kepuasan Kerja sebesar 0,601 dan angka korelasi Stress kerja sebesar 0,285 adalah hasil yang didapat pada kolom Standardized Coefficients (Beta).

- Pada kolom $\mathrm{t}$ digunakan pengujian $\mathrm{t}$ untuk menguji kebenaran dari hipotesis yang ada, dilakukan dengan cara membandingkan nilai $t$ hitung yang telah diperoleh dengan nilai tabel. Kriteria pengujian :

Jika t hitung $>\mathrm{t}$ tabel maka Ho ditolak dan Ha diterima.

Jika $t$ hitung $<\mathrm{t}$ tabel maka Ho diterima dan Ha ditolak.

Pada kolom $t$ diketahui bahwa $t$ hitung untuk Kepuasan Kerja (X1) adalah sebesar 6.361 dengan menggunakan tabel distribusi normal $t$ dan menggunakan tingkat pengujian (1 - alpha) sebesar 95\% dan tingkat kesalahan (alpha) sebesar $5 \%$ serta derajat kebebasan (Degree of Freedom) atau (df) $n-2=80-2=78$, maka diperoleh nilai distribusi tabel $\mathrm{t}$ adalah 1,994. Oleh karena $\mathrm{t}$ hitung pengaruh Kepuasan Kerja lebih besar dari nilai $t$ tabel atau $6.361>1,994$, maka Ho ditolak dan Ha diterima. Sedangkan kolom $t$ hitung untuk Stress kerja (X2) adalah 3,018 dengan menggunakan tabel distribusi normal $\mathrm{t}$ dan menggunakan tingkat pengujian (1 - alpha) sebesar 95\% dan tingkat kesalahan (alpha) sebesar 5\% serta 
derajat kebebasan (Degree Of Freedom) atau (df) $\mathrm{n}-2=80-2=78$, maka diperoleh nilai distribusi tabel $t$ adalah 1,994. Oleh karena $t$ hitung lingkungan kerja lebih besar dari tabel $t$ atau 3,018 > 1,994, maka Ho ditolak dan Ha diterima.

- Pada kolom signifikan digunakan untuk pengujian probabilitas. Kriteria pengujian:

Jika Probabilitas $>0,05$ maka Ho ditolak dan Ha diterima

Jika Probabilitas < 0,05 maka Ho diterima dan Ha ditolak

- Terlihat pada kolom signifikan diketahui nilai probabilitas kepuasan kerja sebesar 0,000, nilai probabilitas stress kerja sebesar 0,000, dengan demikian probabilitas dibawah 0,05 dengan demikian Ho diterima dan Ha ditolak atau koefisien regresi signifikan atau kepuasan kerja dan stress kerja berpengaruh terhadap produktivitas kerja karyawan pada PT. Sinar Surya Baja Profilindo.

\section{KESIMPULAN}

1. Berdasarkan pengujian yang dilakukan dengan melihat angka Sig.F hitung pada tabel Anova SPSS. Berdasarkan hasil perhitungan SPSS, diperoleh angka Sig.F hitung $0.000<0.05$ sehingga dapat diartikan bahwa hipotesis yang diajukan dapat diterima yaitu kepuasan kerja dan stress kerja berpengaruh terhadap produktvitas kerja karyawan pada PT. Sinar Surya Baja Profilindo.

2. Hasil perhitungan menunjukan nilai koefisien korelasi sebesar 0.849 yaitu sekitar $84.9 \%$ yang menyatakan bahwa hubungan kepuasan kerja dan stress kerja terhadap produktivitas karayawan pada PT. Sinar Surya Baja Profilindo sangat kuat.

3. Berdasarkan hasil data frekuensi antara lain yang yang diketahui bahwa : persentase tertinggi yang merasa kurang puas disebabkan oleh gaji, tunjangan, dana pensiun, gaya kepemimpinan. Karaywam dapat menjadi stress di perusahaan tersebut karena : tekanan, macet, perubahan kerja,dan aturan. Sedangkan yang dapat mempengaruhi penurunan produktivitas karyawan di perusahaan tersebut adalah : teknologi, keluhan karyawan, dan quality report

\section{DAFTAR PUSTAKA}

Astianto, A. (2014). Pengaruh stres kerja dan beban kerja terhadap kinerja karyawan pdam surabaya. Jurnal Ilmu \& Riset Manajemen, 3(7), 1-17.

Ferdinand.DBA, A. (2014). Metode Penelitian Manajemen.

Harrisma, O. W., \& Witjaksono, A. D. (2013). Pengaruh Stres Kerja Terhadap Produktivitas Kerja Melalui Kepuasan Kerja. Jurnal Ilmu Manajemen, 1(2).

Hasibuan, D. H. M. (2017). Manajemen Sumber Daya Manusia (revisi). Jakarta: Bumi Aksara.

Lijan Poltak Simanjuntak. (2016). Manajemen Sumber Daya Manusia (1st ed.). Jakarta: Bumi Aksara.

Prof.Dr. Sugiyono. (2016). Metode Penelitian (Cetakan 22). Bandung: Alfabeta.

Prof.Dr.Hj.Sedarmayanti, M.Pd., A. (2017). Perencanaan Dan Pengembangan Sumber Daya Manusia.

Sauermann, J. (2016). Performance measures and worker productivity decisionmaking in policy and management, (May), 1-11. https:/ / doi.org/10.15185/izawol.260 
PRIMANOMICS : JURNAL EKONOMI DAN BISNIS - VOL. 17. No. 3 (2019)

Versi Online Tersedia di : https://jurnal.ubd.ac.id/index.php/ds

| 1412-632X (Cetak) | 2614-6789 (Online) |

T. Hani Handoko. (2014). Manajemen Personalia \& Sumber Daya Manusia (2nd ed.). YOGYAKARTA: BPFE-Yogyakarta. 